\title{
DOES APPLICATION OF ORAL CHLORHEXIDINE DECREASE THE INCIDENCE OF VENTILATOR ASSOCIATED PNEUMONIA IN NEONATES: A RANDOMIZED CONTROLLED TRIAL
}

\author{
N. Gupta ${ }^{1}$, S. Dutta ${ }^{1}$, P. Kumar ${ }^{1}$, P. Ray ${ }^{2}$, A.K. Saxena ${ }^{3}$ \\ ${ }^{1}$ Pediatrics, ${ }^{2}$ Microbiology, ${ }^{3}$ Radiodiagnosis, PGIMER, Chandigarh, India
}

Background and aim: Oral chlorhexidine (CHX) application decreases the incidence of ventilator associated pneumonia (VAP) in adults. This study aimed to determine the effectiveness of oral CHX application in decreasing the incidence of VAP in neonates.

Method: In this open-label controlled trial, neonates requiring endotracheal intubation for mechanical ventilation were randomly assigned to 'chlorhexidine' and 'no chlorhexidine' group. The CHX group received applications of CHX ( $0.2 \%$ w/v, Chlorhex Plus, Dr. Reddy's Laboratory, Hyderabad, India) every 8hrs from randomization until extubation, by a cotton applicator on the oral mucosa. The control group received standard care. The primary outcome was number of episodes of VAP per 1000 person-ventilation hours. VAP was defined using standard CDC criteria for infants $<1$ year of age.

Results: One hundred four neonates were enrolled $(\mathrm{CHX}=51$, control $=53)$. The mean gestation was $32.4 \pm 4$ and 32.9 3.4 weeks, while the median [IQR] age at intubation was 48.0 [26.0, 219.0] and 50.0 [13.0, 130.0] hours in CHX and control groups respectively. The incidence rate of VAP was 1.9 and 2.6 episodes per 1000 person-ventilation hours in CHX and control groups respectively [incidence rate difference $=-0.7$ (95\% CI: 2.5 to1.1, $\mathrm{p}=0.4)$ ]. No subject had local or systemic adverse reactions to CHX.

Conclusion: Oral application of CHX was well tolerated in neonates. However, it did not decrease the incidence of VAP significantly. 